\title{
Detection of Mercury in Water using Filter Paper Based Channel and Colorimetric-Android Readout
}

\author{
Gurushree Dindorkar, Vishal Rathee, Suresh Balpande, Jayu Kalambe
}

\begin{abstract}
The heavy metals dissolved in water are exceptionally unsafe to human and marine health which causes numerious medical complications. This paper demonstrates the use of a Microfluidic paper-based channel ( $\mu$ PAD) and an easyto-use colorimetric android based application for the accurate detection of heavy metal Mercury $\left(\mathrm{Hg}^{2+}\right)$ in water. Gold Nanoparticles (AuNPs) functionalized with Papain and 2,6pyridinedicarboxylic acid is used to detect $\mathrm{Hg}$ for further colorimetric analysis. Droplet-based Microfluidic channel in star shape with a paper-based stencil, a hydrophobic barrier and a hydrophilic channel using Polyvinyl Alcohol (PVA) was created for this. Colorimetric detection is used to create a database which is used to calibrate the color range for other unknown quantities of Mercury $\left(\mathrm{Hg}^{2+}\right)$ present in water. This experimental database was used to create a user-friendly Android Application based display. The real-time android application was calibrated to quantify mercury concentrations from $0.1 \mathrm{~g} /$ Litre to $0.001 \mathrm{mg} /$ Litre by observing a change in color from red to blue. This built platform can be utilized as a basic low-cost and portable system for various other fluid testings.
\end{abstract}

Keywords: Mercury, Colorimetric Detection, Gold Nanoparticles, $\mu P A D$ s based detection.

\section{INTRODUCTION}

Dealing with Heavy metal pollutants is an intense issue in making the environment pollution free for over a decade. Different heavy metals such as Mercury (Hg), Lead (Pb), Cadmium (Cd), Arsenic (As), Nickel (Ni) can be exceptionally unsafe to bio-system and biological activities because they can cause severe medical problems in living things. Accessibility of harmful heavy metal ions in water or aquatic ecosystems has genuine health impacts like osteoporosis, Alzheimer's disease, mental retardation in addition to that these ions are carcinogenic. Hence detection of such harmful metals proved to be a good topic of interest [1]. There are different methodologies that are used for detecting the presence of heavy metals in water. These methods require huge instruments and laboratories that are costly in nature, leading to large investments, need

Revised Manuscript Received on December 30, 2019.

* Correspondence Author

Gurushree Dindorkar*, Research Scholar, Department of Electronics Engineering, Shri Ramdeobaba College of Engineering and Management, Nagpur, India.

Vishal Rathee, Assistant Professor, Department of Electronics Engineering Shri Ramdeobaba College of Engineering and Management, Nagpur, India.

Suresh Balpande, Assistant Professor, Department of Electronics Engineering, Shri Ramdeobaba College of Engineering and Management, Nagpur, India.

Jayu Kalambe, Associate Professor, Department of Electronics Engineering, Shri Ramdeobaba College of Engineering and Management, Nagpur, India.

(C) The Authors. Published by Blue Eyes Intelligence Engineering and Sciences Publication (BEIESP). This is an open access article under the CC BY-NC-ND license (http://creativecommons.org/licenses/by-nc-nd/4.0/) skilled labors for its operation and an enormous amount of reagents and solvents that need proper storage and handling facility. Some of the most commonly employed methods are Atomic Absorption Spectrometry (AAS), Surface Enhanced Raman Spectroscopy (SERS), Inductively Coupled Plasma Mass Spectrometry (ICP-MS), and Fluorescence Spectrometer [2][3][4]. Thus there arises a need for generating resources and facilities that are cost-effective, maneuverable and simple to operate requiring lesser amounts of reagents and have quicker recognition and display system. In recent times, Gold Nanoparticles (AuNP) are getting colossal consideration for its widespread utility in applications for detection and sensing metals, because of its colorimetric sensing properties. Gold Nanoparticles (AuNP) are exceedingly powerful for colorimetric sensing on account of its high visible range extinction coefficient and color-tunable activity that relies upon the interparticle size [5][6][7]. Recently, extensive research is being garnered for heavy metal detection, particularly with Gold Nanoparticles being a significant factor in nanoscale materials and devices. The AuNP-based colorimetric detector is commonly used to detect small to very small concentrations of heavy metal ions [8][9][10][11]. In this paper, we have discussed a simple colorimetric process for the detection of mercury ions $\left(\mathrm{Hg}^{2+}\right)$ in water, using the Papain and 2,6-pyridinedicarboxylic acid functionalized AuNPs. An experiment where only papain was considered for the detection of Mercury ions demonstrated that it immediately reacts with $\mathrm{Hg}^{2+}$ and the color changes from red to blue. However, papain was also found to demonstrate color-changing response to other metals like (Lead) $\mathrm{Pb}^{2+}$ and (Copper) $\mathrm{Cu}^{2+}$ in the AuNP solution. Thus, to attain extremely high selectivity for $\mathrm{Hg}^{2+}$ ions we have used 2,6-pyridinedicarboxylic acid along with papain. Thus, in its presence, Papain and $\mathrm{Hg}^{2+}$ react together, to form $\mathrm{Au}-\mathrm{S}$ whereas $\mathrm{Pb}^{2+}$ and $\mathrm{Cu}^{2+}$ are isolated.

\section{MATERIALS AND METHODS}

\section{A. Materials}

Chloroauric acid $\left(\mathrm{HAuCl}_{4}\right)$ in powder form, Papain papaya extract, 2,6-Pyridinedicarboxylic Acid-99\% Pure (PDCA), Mercuric Sulphate, Polyvinyl Alcohol (PVA-powder)- 9899\% Hydrolysis. The reagents did not require further cleansing and all the solutions were prepared in adequate quantity of Deionized Water (DI) water.

\section{B. Preparation of AuNPs}

AuNPs were processed using the $\mathrm{HAuCL}_{4}$ Citrate Reduction Method [12][13]. All the glassware were first cleaned by acetone and washed with DI water and were vacuum-dried completely at $60^{\circ} \mathrm{C}$ for 15 mins. 
The aqueous solution of HAuCl4 $(0.5 \mathrm{mM}, 200 \mathrm{ml})$ was first prepared by dissolving HAuCl4 powder in distilled water and stirred till pale yellow color appeared. This 200ml solution of $\mathrm{HAuCl} 4$ was then boiled in a beaker till dense vapor appears and then the aqueous solution is stirred rapidly for another $10 \mathrm{~min}$. $20 \mathrm{ml}$ of $38.8 \mathrm{mM}$ Trisodium Citrate solution is then poured in the boiling mixture and stirred continuously till color changes. As the trisodium citrate is added to the solution, the pale yellow solution first becomes colorless (Figure 1a) and on further boiling, the solution turns blue. Gradually the blue color changes to purple and then to Ruby Red. This red solution is stirred further at room temperature for another 15 minutes to obtain homogenous color and then left overnight to cool at room temperature (Figure 1b).

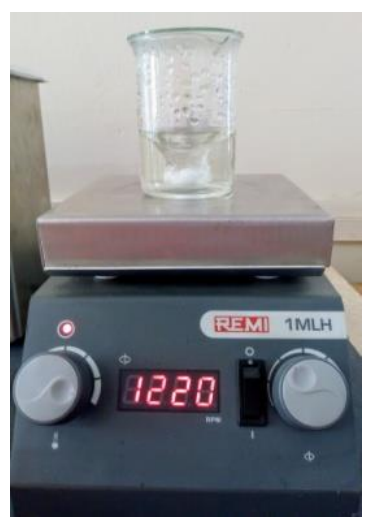

(a)

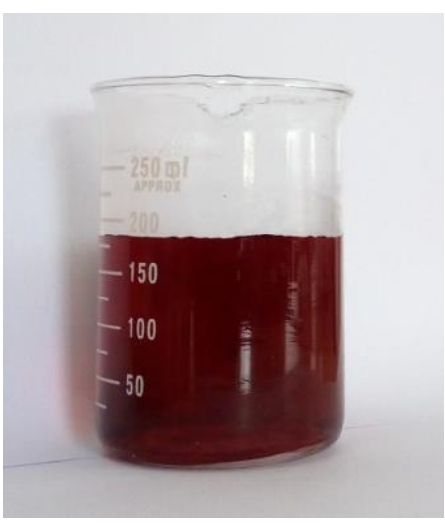

(b)
Figure 1: (a) Aqueous solution of $\mathrm{HAuCl}_{4}$ being boiled and stirred. (b) Red-colored Gold Nanoparticle (AuNPs) Solution.

\section{Preparation of $\mathbf{H g}^{2+}$ Sample}

Multiple aqueous samples containing mercury (Hg) with varied concentrations were prepared for testing [14]. Initially, the stock standard solution of mercury $(1.0 \mathrm{gm} / \mathrm{L})$ was prepared by dissolving $0.148 \mathrm{~g}, \mathrm{HgSO}_{4}$ in $10 \mathrm{ml}$ of water along with mercuric sulphate. Since mercuric sulphate does not dissolve in pure water and a yellow precipitate is formed when mixed with water, $0.83 \mathrm{~mL}$ of concentrated $\mathrm{H}_{2} \mathrm{SO}_{4}$ is added to the solution that produces an exothermic reaction and the solution becomes colorless. Different concentrations (0.1g, 0.05g, 0.025g, 0.0125g, 6.25mg, $3.12 \mathrm{mg}, 1.56 \mathrm{mg}$, $0.78 \mathrm{mg}, \quad 0.39 \mathrm{mg}, 0.19 \mathrm{mg}, 0.09 \mathrm{mg}, 0.04 \mathrm{mg}, 0.02 \mathrm{mg}$, $0.006 \mathrm{mg}, 0.003 \mathrm{mg}, 0.001 \mathrm{mg}$ ) of Hg working solutions were prepared by further diluting the stock solution with DI water. Numerous colorimetric tests were carried out on this stock solution using $\mu$ PADs. Stock solution was also used to spike the actual samples of water with known levels of mercury for checking its presence in it.

\section{Preparation of P-PDCA-AuNPs}

Papain only functionalized AuNPs does not give high selectivity to Mercury and are also responsive to Cadmium and Lead. To achieve exclusivity and high sensitivity of AuNPs to mercury, nanoparticles are functionalized with papain and 2,6-Pyridinedicarboxylix Acid [15]. Solid papain is dissolved in water to prepare P-PDCA-AuNPs solution $(0.1 \mu \mathrm{M})$. Papain is added in abundance to AuNPs ensuring that AuNPs are completely functionalized. 2,6pyridinedicarboxylic acid (PDCA) based water solution $(0.5 \mathrm{mM})$ is also prepared using Deionized water. Papain and 2,6-pyridinedicarboxylic (PDCA) acid solutions are then added to the AuNP solution, one at a time which requires settling time to form a homogenous mixture. First, the Papain based aqueous solution was added to the sample containing $\mathrm{Hg}$ and the resultant solution after being stirred for 30 minutes was kept in dark for around 6 hours. PDCA solution was then added to the P-AuNPS and the mixture stirred again for 30 minutes and kept away from light for another 6 hours. This Functionalized P-PDCA-AuNPs were used as a reagent for the colorimetric testing to determine the presence of Mercury in water.

\section{E. Fabrication of $\mu$ PADs}

$\mu$ PADs using stencil-based channels and PDMS are already developed [16][17][18]. But here an approach involving Polyvinyl Alcohol-based barriers on the paper stencil for the generation of $\mu$ PADs was employed for its simplicity and non-reactiveness with sample and reagents. The $\mu$ PADs were developed by depositing the PVA solution as a hydrophobic barrier thus preventing the diverging of the sample and reagents on paper. For this, the PVA solution was prepared by mixing 25 grams of polyvinyl alcohol (PVA) in 1000 grams of water. The solution was stirred on a magnetic stirrer for 120 min to get uniform viscous solution which was subsequently sieved using a $25 \mu \mathrm{m}$ sieve to remove suspended particles. Thus $\mu$ PADs without costly tools were designed and developed in various shapes using a paper stencil.

The stepwise fabrication of $\mu$ PADs is shown in Figure 2.
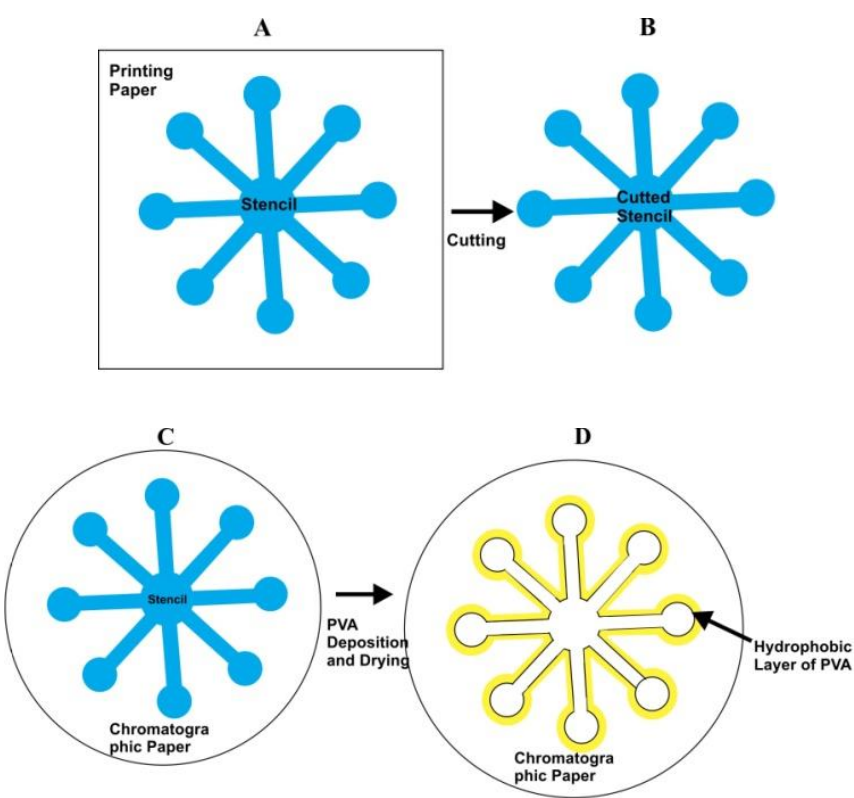

Figure 2: (A) Stencil printed on printing paper. (B) Cutout of the Stencil (C) Stencil on chromatographic paper (D) Final fabricated $\mu$ PAD with PVA Layer.

The designed paper mask was accomplished by first printing an example structure carefully onto a trace printing paper using an ink-jet laser printer (Canon LBP 2900B), trailed by carving along the designed pattern. The $\mu$ PADs were developed in a star-shaped pattern, with 8 test zones each of $7 \mathrm{~mm}$ diameter. The middle control area, with a diameter of $9 \mathrm{~mm}$, was used to connect each of the seven test points by channels. The width of the channel was kept $2 \mathrm{~mm}$ so as to permit non-delayed concurrent responses in all sample zones for different concentrations of samples [19].

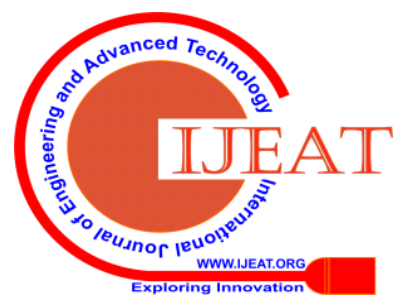


The printed design was cut along the borders and kept on a chromatograph Whatman filter paper, and thick aqueous PVA (Polyvinyl Alcohol) was then deposited along the borders, to draw the hydrophobic barriers which would prevent spreading of sample and reagents.The PVA was coated in such a way so that even if the sample and reagents infiltrates the chromatography paper from both sides (i.e. back and front), a well defined and distinct barrier would exist between the test points. The PVA coated filter paper was allowed to dry on a hot plate at $80^{\circ} \mathrm{C}$ for $5 \mathrm{mins}$. Fabricated structure with hydrophobic and hydrophilic channels is shown in Figure 3.

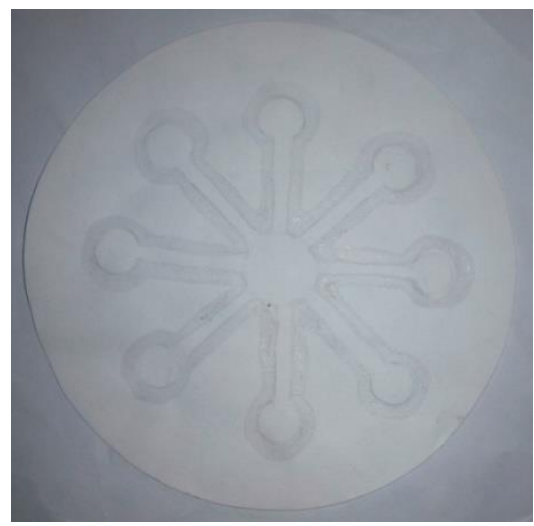

Figure 3: Fabricated $\mu$ PAD with the PVA barrier. F. Colorimetric Detection using $\mu$ PADs

Colorimetric detection of $\mathrm{Hg}$ was carried out to estimate the amount of mercury present in water using $\mu$ PADs which requires very small quantities of chemicals [21]. A series of test samples containing different concentrations of $\mathrm{Hg}$ were prepared and analyzed with AuNP solution and the corresponding color changes were recorded. Different samples containing $\mathrm{Hg}$ within a range of $0.1 \mathrm{~g}$ to $0.001 \mathrm{mg}$ were poured on different test points of $\mu$ PADs.

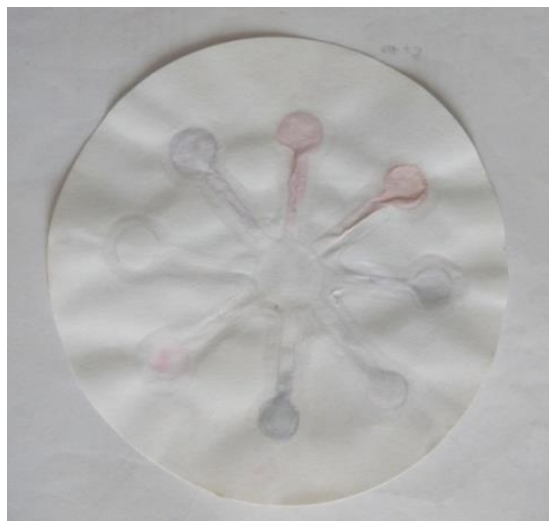

Figure 4: $\boldsymbol{\mu P A D}$ with different concentrations of $\mathbf{H g}$. A few drops of P-PDCA-AuNPs solution was then dropped onto the same test points and the corresponding color change was recorded with the help of a camera and database was prepared. This database demonstrates the ability for successful detection of unknown concentrations of mercury in water within the specified range. The change in color is quite prominent and can be observed with naked eyes (Figure 4). The test points can be reused by properly removing the previously present colored sample-reagent combination from the $\mu$ PADs with the help of DI water. This detection technique was restricted by the absence of a high-resolution camera integrated in the automatic detection and display of photodiodes.

\section{G. Color detection using ImageJ Software.}

ImageJ software was used to find the color intensity of recorded samples deposited on the $\mu$ PADs and thus calculate the near exact quantity of mercury $\left(\mathrm{Hg}^{2+}\right)$ content present. The mean color intensity of each zone on the $\mu \mathrm{PAD}$ was determined using the measurement tool from the image toolbar of ImageJ. Initially, the area of interest demonstrating color change is marked by using a circle tool from the tool tray and then the average color intensity of the selected area is easily obtained. Figure 6 shows the test sample calibration curve, i.e. $\mathrm{mg} / \mathrm{L}$ to mean color intensity graph obtained using ImageJ.

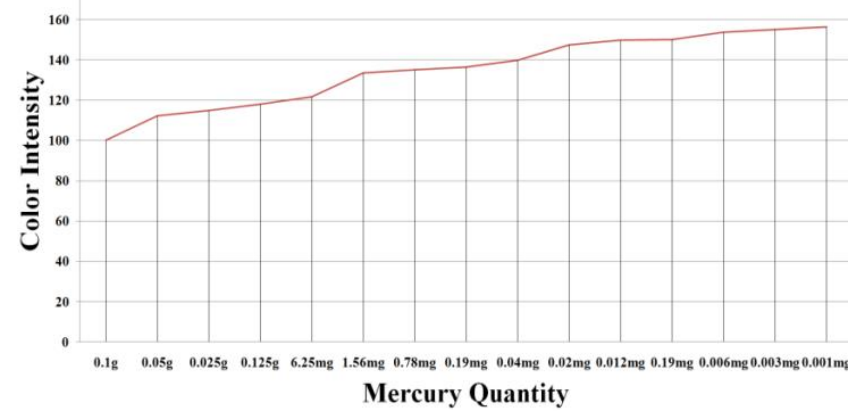

Figure 6: Calibration curve: detection of Mercury with varied color intensity of samples.

\section{H. Applicability in Real Water Samples}

To counter the effect of error in the absence of a highresolution camera and determine the effectiveness of this whole process in the presence of impurities with mercury in water, different water samples from various sources were collected in larger quantities $(\mathrm{ml})$ from the nearby areas. The impure water samples were stored in test tubes at room temperature and spiked by adding known quantities of mercury solutions [15][20] for further analysis (Figure 5). Colorimetric tests were carried out after adding P-PDCAAuNPs solution to the contaminated water samples and stirring it for some time to get uniform color change. The images of the colorimetric tests were used to prepare a database that would help predict the concentration of unknown quantities of mercury present in the water.

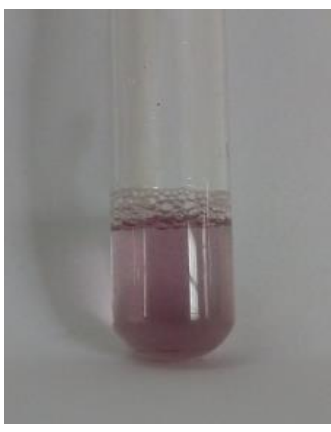

(a)

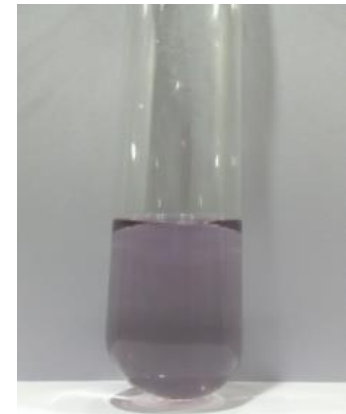

(b)
Figure 5: (a) Absence of $\mathrm{Hg}$ in water Sample. (b) presence of $\mathrm{Hg}$ in the water sample. 


\section{Hg Detection through Android Application}

An android application based on colorimetric detection was formulated which could display the concentration of mercury present in the contaminated water. The android application could detect the color intensity of the samples from the picture taken using a phone camera, analyze it based on the preferred threshold values from the database [22] and then display the output message showing the exact quantity of Mercury $\left(\mathrm{Hg}^{2+}\right)$ present in water. It is also customized to instruct whether the water is safe for drinking or not. Figure 7 shows the App screen displaying a pretested sample with $0.05 \mathrm{~g}$ of mercury present.

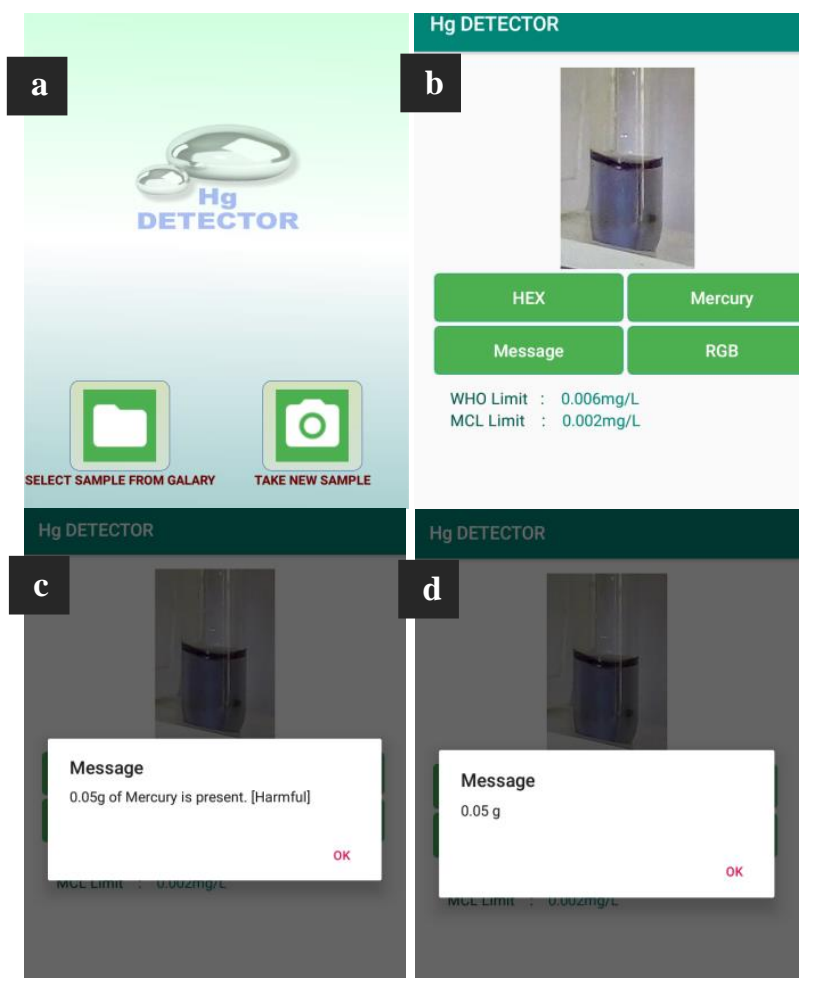

Figure 7: a) Home page of Android Application b) Message buttons and Selected Sample c) Message box d) Mercury concentration.

The application's versatility lies in the fact that it can efficiently work using a standard phone camera with a resolution of $8 \mathrm{MP}, \mathrm{f} / 2.2$ (focal length), $1.12 \mu \mathrm{m}$ (pixel rate), that was also used to prepare the database. The average value of colored pixels present on the test zone of the $\mu$ PADs was determined using an image processing algorithm which was used to set up the database. It was revalidated that the sensitivity and selectivity of AuNPs rely on a lot of factors such as particle size, concentration, nature, density, $\mathrm{pH}$ and temperature [23][24].

\section{RESULTS AND CONCLUSION}

In this paper, a simple, rapid, cost-effective method of water analysis determining the presence and proportion of mercury is demonstrated. A user-friendly display technique is also proposed and implemented. Using the fact that many metal ions react with the carboxylic group and amino acids like PDCA and increase their selectivity and sensitivity, 2,6pyridinedicarboxylic acid and Papain was used for functionalizing AuNPs for the detection of mercury $\left(\mathrm{Hg}^{2+}\right)$. As the concentration of mercury increases, the color of the solution changed from red to violet and then to blackish blue (Figure 8).
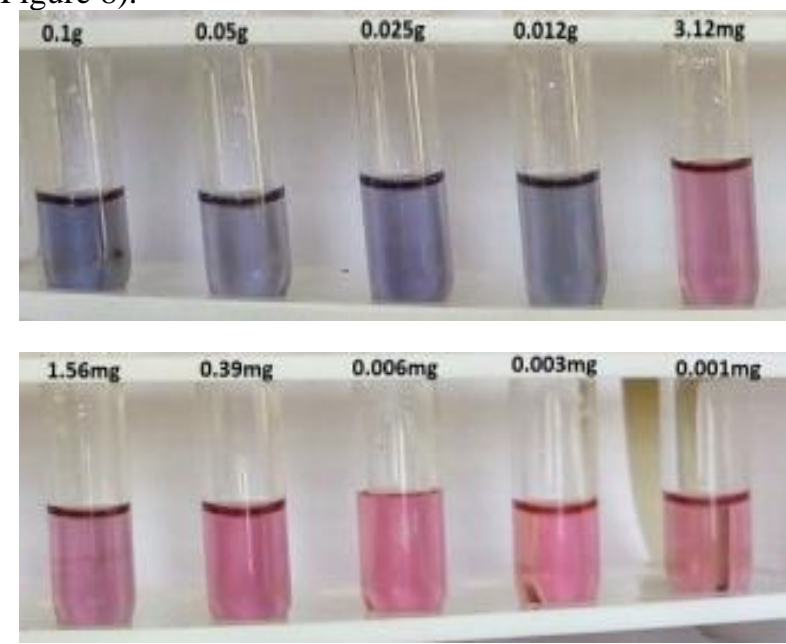

Figure 8: Water samples with mercury in the range of $0.1 \mathrm{~g}$ to $0.001 \mathrm{mg}$

The color variation as observed in $\mu$ PADs and even in the test tube sample was marred by the proportions of the sample, the quantity of reagents used, the physical dimensions of the $\mu$ PADs, the resolution of the camera and the environmental conditions. Thus, when the concentration of Mercury $\left(\mathrm{Hg}^{2+}\right)$ was increased above $0.1 \mathrm{~g} / \mathrm{L}$, no significant color change was observed indicating that most all the AuNPs were already aggregated. The system showed the capability to detect harmful proportions of mercury surrounding $0.002 \mathrm{mg} / \mathrm{L}$ mark as provided by WHO and can also be calibrated employing suitable changes in reagents to detect other harmful chemicals and metals in fluids.

\section{ACKNOWLEDGMENT}

The authors wish to thank Suroosh Ali, Bhavishya Waghwani, Pranjali Chakole, Dr. Suraj Butolia, and Dr. C. Pandhurnekar, RCOEM, Nagpur for their technical support and guidance. We acknowledge the MEMS Laboratory in the Electronics Engineering Department at Shri. Ramdeobaba College of Engineering and Management, Nagpur for providing the necessary lab facilities and financial support under research seed money grant for this project.

\section{REFERENCES}

1. Suroosh Ali, Vishal Rathee, Jayu Kalambe, Suresh S. Balpande, Cadmium Contaminated Water Detection with Interdigitated Electrodes and Microfluidic System ,International Journal of Engineering and Advanced Technology (IJEAT) ISSN: 2249-8958, Volume-8 Issue-5, June 2019.

2. Hung, Y., Hsiung, T., Chen, Y., Huang, Y. and Huang, C. (2010). Colorimetric Detection of Heavy Metal Ions Using Label-Free Gold Nanoparticles and Alkanethiols. The Journal of Physical Chemistry C, 114(39), pp.16329-16334.

3. Karthikeyan, K. and Sujatha, L. (2017). Design and fabrication of microfluidic device for mercury ions detection in water. 2017 International Conference on Nextgen Electronic Technologies: Silicon to Software (ICNETS2).

4. Lou, T., Chen, Z., Wang, Y. and Chen, L. (2011). Blue-to-Red Colorimetric Sensing Strategy for Hg2+ and Ag+ via Redox-Regulated Surface Chemistry of Gold Nanoparticles. ACS Applied Materials \& Interfaces, 3(5), pp.1568-1573.

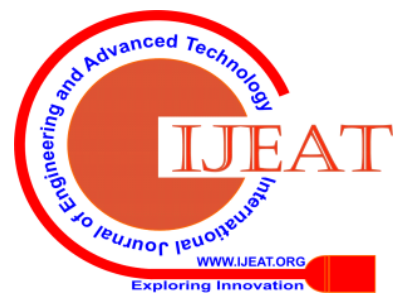


5. Aulsebrook, M., Watkins, E., Grace, M., Graham, B. and Tuck, K. (2018). Modified Gold Nanoparticles for the Temperature-Dependent Colorimetric Detection of Mercury and Methylmercury. Chemistry Select, 3(7), pp.2088-2091.

6. Firdaus, M., Fitriani, I., Wyantuti, S., Hartati, Y., Khaydarov, R., Mcalister, J., Obata, H. and Gamo, T. (2017). Colorimetric Detection of Mercury(II) Ion in Aqueous Solution Using Silver Nanoparticles. Analytical Sciences, 33(7), pp.831-837.

7. Kumar, S., Gandhi, K. and Kumar, R. (2007). Modeling of Formation of Gold Nanoparticles by Citrate Method†. Industrial \& Engineering Chemistry Research, 46(10), pp.3128-3136.

8. Baghel A., Singh B., Pandey P., and Sekhar K. (2007). A Rapid Field Detection Method for Arsenic in Drinking Water. Analytical Sciences, 23(2), pp.135-137.

9. Du, J., Yin, S., Jiang, L., Ma, B. and Chen, X. (2013). A colorimetric logic gate based on free gold nanoparticles and the coordination strategy between melamine and mercury ions. Chem. Commun., 49(39), pp.4196-4198.

10. Kim, H., Ren, W., Kim, J. and Yoon, J. (2012). ChemInform Abstract: Fluorescent and Colorimetric Sensors for Detection of Lead, Cadmium, and Mercury Ions. ChemInform, 43(29), p.no-no.

11. Lin, Y., Huang, C. and Chang, H. (2011). Gold nanoparticle probes for the detection of mercury, lead and copper ions. The Analyst, 136(5), pp.863-871.

12. Kimling, J., Maier, M., Okenve, B., Kotaidis, V., Ballot, H. and Plech, A. (2006). Turkevich Method for Gold Nanoparticle Synthesis Revisited. The Journal of Physical Chemistry B, 110(32), pp.1570015707.

13. Pranjali Chakole, Vishal Rathee, Jayu Kalambe, Prasanna Kulkarni, Suresh S. Balpande, Design and Development of Triboelectric Blue Energy Harvester" ,International Journal of Engineering and Advanced Technology (IJEAT) ISSN: 2249-8958, Volume-8 Issue-5, June 2019.

14. Cai, L., Fang, Y., Mo, Y., Huang, Y., Xu, C., Zhang, Z. and Wang, M. (2017). Visual quantification of $\mathrm{Hg}$ on a microfluidic paper-based analytical device using distance-based detection technique. AIP Advances, 7(8), p.085214.

15. Lai, C., Qin, L., Zeng, G., Liu, Y., Huang, D., Zhang, C., Xu, P., Cheng, M., Qin, X. and Wang, M. (2016). Sensitive and selective detection of mercury ions based on papain and 2,6pyridinedicarboxylic acid functionalized gold nanoparticles. RSC Advances, 6(4), pp.3259-3266.

16. Mohammadi, S., Maeki, M., Mohamadi, R., Ishida, A., Tani, H. and Tokeshi, M. (2015). An instrument-free, screen-printed paper microfluidic device that enables bio and chemical sensing. The Analyst, 140(19), pp.6493-6499.

17. Shangguan, J., Liu, Y., Pan, J., Xu, B., Xu, J. and Chen, H. (2017) Microfluidic PDMS on paper (POP) devices. Lab on a Chip, 17(1), pp.120-127.

18. Rewatkar Prakash \& Balpande Suresh \& Kalambe Jayu. (2018). Design and Development of PDMS based Channel for Fluid Analysis. Indian Journal of Science and Technology. 11. 1-6. 10.17485/ijst/2018/v11i36/96827.

19. Xie, L., Zi, X., Zeng, H., Sun, J., Xu, L. and Chen, S. (2019). Lowcost fabrication of a paper-based microfluidic using a folded pattern paper. Analytica Chimica Acta, 1053, pp.131-138.

20. Guo, Y., Wang, Z., Qu, W., Shao, H. and Jiang, X. (2011). Colorimetric detection of mercury, lead and copper ions simultaneously using protein-functionalized gold nanoparticles. Biosensors and Bioelectronics, 26(10), pp.4064-4069.

21. Xing, C., Liu, L., Zhang, X., Kuang, H. and Xu, C. (2014) Colorimetric detection of mercury based on a strip sensor. Anal. Methods, 6(16), pp.6247-6253.

22. Salve M., Rana S., Dindorkar, G., Rewatkar, P. and Kalambe, J. (2019). Development of Microfluidics-Based Quantitative Adulteration Detection Platform. Sensor Letters, 17(1), pp.41-45.

23. Chansuvarn, W. and Imyim, A. (2011). Visual and colorimetric detection of mercury (II) ion using gold nanoparticles stabilized with a dithia-diaza ligand. Microchimica Acta, 176(1-2), pp.57-64.

24. Jana, N., Gearheart, L. and Murphy, C. (2001). Seeding Growth for Size Control of 5-40 nm Diameter Gold Nanoparticles. Langmuir, 17(22), pp.6782-6786.

\section{AUTHORS PROFILE}

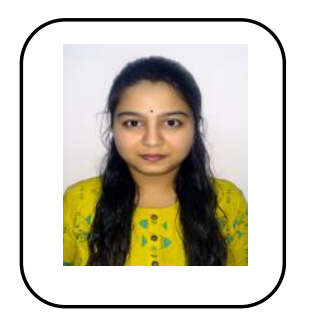

Gurushree Dindorkar graduated in 2016 with a Bachelor of Electronics Engineering degree and is currently pursuing her Master's degree in VLSI Design from Ramdeobaba College of Engineering and management, Nagpur.

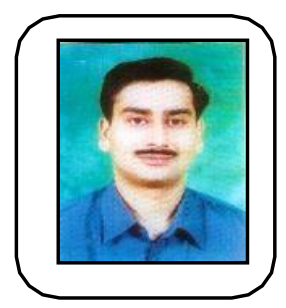

Vishal Rathee is Assistant Professor at the Ramdeobaba College of Engineering and Management, Nagpur. He received his Bachelor of Electronics and Telecommunications Engineering in 2002. He graduated in 2007 with a Master's degree in electronics engineering. His fields of interests are Microsystems and soft computing. More than 10 articles have been written by the International Conference/Journal. He is also a member of ISTE and ISSS.

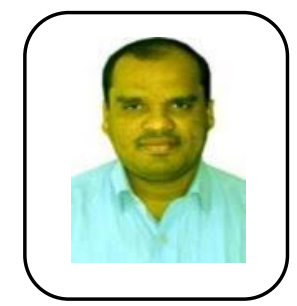

Suresh S. Balpande is an Assistant Professor at Shri. Ramdeobaba College of Engineering and Management, Nagpur and he has received his Master's degree in Digital Electronics with honors and then carried out his doctoral research in the area of Energy Harvesting Systems. His research interests are MEMS sensors, Industrial Automation and Mechatronics. Thirty journal publications, conferences at the international and national level are credited to him. He is also a member of ISTE, IETE and ISSS.

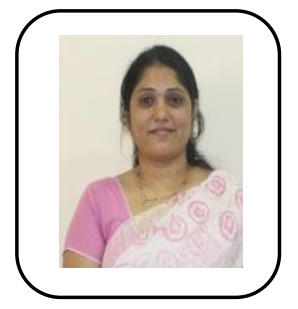

Jayu Kalambe is an Associate Professor at Shri Ramdeobaba College of Engineering and Management, Nagpur. She has received her Master's degree and Ph.D. in Electronics engineering from the Visveswaraya Nationa Insitute of Technology, Nagpur. Her research area includes design and analysis of microcantilever-based sensor. Through national and international conferences, she has authored more than 30 articles, six papers through international journals, and one patent. She is an ISTE, IEEE and ISSS member. 